\title{
Changes in cFLIP expression in the corpus luteum throughout the estrous cycle of Shibagoats
}

\author{
H.Z. Jin, Y. Wang, Y. Liu, X.P. Li and Y. Jin \\ Agricultural College of Yanbian University, Yanji, Jilin, China \\ Corresponding author: Y. Jin \\ E-mail: yijin@ybu.edu.cn
}

Genet. Mol. Res. 14 (4): 12955-12966 (2015)

Received May 26, 2015

Accepted July 14, 2015

Published October 21, 2015

DOI http://dx.doi.org/10.4238/2015.October.21.16

\begin{abstract}
Changes in the expression of the anti-apoptotic protein cFLIP (cellular FLICE inhibitory protein) were examined in the caprine corpus luteum (CL), during development and subsequent maintenance. Corpora lutea at four different stages were collected from Shiba goats, to measure the expression of cFLIP mRNA, protein and immunolocalization. Expression of short form cFLIP (cFLIP ${ }_{s}$ ) mRNA was highest at the early $C L$ stage, and decreased during late and regressed stages $(P<0.05)$. In contrast, long form cFLIP ( $\left.c F L I P_{L}\right)$ mRNA expression was high during early, mid and late stages, and only decreased at the regressed stage $(P<0.01)$. Protein expression of $\mathrm{CFLIP}_{\mathrm{S}}$ was highest at the late $\mathrm{CL}$ stage, and decreased the regressed stage $(P<0.01)$. Protein expression of $c F L I P_{L}$ was highest at the early and mid $C L$ stages, and decreased by the late and regressed stages $(P<0.01)$. Further expression of $C F L I P_{L}$ was higher at the early $C L$ stage than at the mid stage $(P<0.01)$. cFLIP protein expression was detectable by immunostaining in the early, mid and late CL stages, but not at the regressed $\mathrm{CL}$ stage. These results are consistent with the hypothesis that CFLIP acts as a survival factor in the maintenance of $\mathrm{CL}$ function in goats.
\end{abstract}

Key words: Cellular FLICE inhibitory protein; Corpus luteum; Apoptosis; Estrous cycle; Shiba goat 


\section{INTRODUCTION}

Apoptosis - programmed cell death in the absence of an inflammatory reaction - is characterized by membrane blebbing, cellular retraction, DNA fragmentation and apoptotic body formation (Johnson and Bridgham, 2002).

During the mammalian ovarian cycle, follicular growth, maturation, ovulation and luteinization are controlled by cellular signals from follicle-stimulating $(\mathrm{FSH})$ and luteinizing (LH) hormones. During growth and development, more than $99 \%$ of follicles undergo atresia, and less than $1 \%$ develop to the preovulatory and subsequent ovulation stages (Hughes and Gorospe, 1991; Tilly et al., 1991).

In the mammalian ovary, cell death occurs during follicular atresia and luteolysis (Sakamaki et al., 1997). Luteolysis is the process of regression of luteal cells formed in the CL after ovulation. It has been suggested that Fas-ligand is the major mechanism regulating luteal cell apoptosis during luteolysis (Juengel et al., 1993; Rueda et al., 1995; Shikone et al., 1996; Bowen et al., 1999; Roughton et al., 1999; Komatsu et al., 2003). Apoptosis is induced by death ligands and is a critical biological process, particularly in the immune system. Apoptosis can be initiated through engagement of certain members of the tumor necrosis factor (TNF) receptor super-family, such as Fas, Fas ligand (FasL), TNF- $\alpha$, and TNF-related apoptosis-inducing ligand (TRAIL). When a death ligand binds to a death receptor on the cell membrane, an apoptotic signal is transduced into the cell. The Fas-mediated apoptosis signaling pathway has been suggested to operate as follows: Fas is activated through the binding of FasL to its extracellular domain; the Fas-associated death domain (FADD) protein binds to the intracellular domain of the activated Fas molecule, through its DD;procaspase-8 binds to FADD through the death effector domain (DED)and becomes activated; and finally, activated caspase- 8 initiates the activation of procaspase-3 to caspase-3, which in turn activates cellular nucleases, and apoptosis is induced (Nagata,1997).

Recent studies have suggested that cFLIP may act as an anti-apoptosis factor in the granulosa cells of porcine follicles (Matsuda-Minehata et al., 2005). cFLIP is also known as CASH, Casper, CLARP, FLAME, or IFLICE. In humans, cFLIP occurs in two isoforms, designated short form $\left(c F L I P_{S}\right)$ and long form (cFLIP $)$. cFLIP is a homologue of procaspase-8, and consists of two death effector domains (DED) and a pseudo-enzyme domain. The short form consists of two DEDs, which are similar to those employed by procaspase-8 to polymerize and bind to FADD.In addition to two DEDs, cFLIP $\mathrm{L}_{\mathrm{L}}$ contains a pseudo-enzyme domain, which is similar to the functional enzymatic domain of procaspase-8but completely lacks enzymatic activity (Irmler et al.,1997). Both forms of cFLIP inhibit apoptosis (particularly Fas-mediated) by competing with procaspase-8 and blocking its function, thereby potently inhibiting cell death receptor-mediated apoptosis signal transduction (Krueger et al., 2001; Thome and Tschopp, 2001).

Expression of cFLIP has been demonstrated in healthy ovarian follicular granulosa cells of Shiba goats. The Shiba is a Japanese miniature goat and is a non-seasonal breeder under natural daylight (Kano et al., 1977). In the female, age at puberty is approximately 7 months (Sakurai et al., 2004). Estrus lasts approximately $22 \mathrm{~h}$ and is followed by a mean estrous cycle period of 21 days (range 19 to 23 days), if fertilization is successful (Mori and Kano, 1984). The Shiba goat is considered a promising model for the application of molecular biological analyses in the study of ruminant reproduction (Mogi et al., 2002). 


\section{MATERIAL AND METHODS}

\section{Experimental design and CL collection}

Four adult female Shibagoats, each weighing at least $30 \mathrm{~kg}$ and with normal estrous cycles, were used in the study. Animals were sourced from the animal resource science center of the University of Tokyo. They were housed under natural conditions of day length and temperature, fed concentrates and hay, and had free access to water. Experiments were conducted in accordance with the Guidelines for Animal Welfare in Research. For each goat, the estrous cycle was monitored daily by transrectal ultrasonographic examination, and follicular ovulation was monitored daily for 2 consecutive estrous cycles. Following the second natural (spontaneous) ovulation (designated day 0), ovaries were surgically harvested from the four goats on days 3, 8, 17 and 20; these time points corresponded to, respectively, days 21,21,23 and 22 of the normal estrous cycle for each animal.

Luteal tissue was sliced with a razor blade into small pieces, frozen in liquid nitrogen and stored at $-80^{\circ} \mathrm{C}$ until processing for mRNA and protein expression analyses. For histology and immunohistochemistry, portions of CL were fixed for 48 to $72 \mathrm{~h}$ in $10 \%$ neutral formalin (v/v; $\mathrm{pH}$ 7.4), and embedded in paraffin wax.

\section{Plasma progesterone concentration analysis}

Blood samples were collected into heparinized tubes by jugular venipuncture. Plasma was collected immediately by centrifugation of blood at $2000 \mathrm{~g}$ for $30 \mathrm{~min}$ at $4^{\circ} \mathrm{C}$, and the stored at $-20^{\circ} \mathrm{C}$ for subsequent analysis. Steroids were extracted from supernatants using diethyl ether. Two extracts (each $50 \mu \mathrm{L}$ with $2 \mathrm{~mL}$ diethyl ether) were taken into glass tubes from each sample. Extracted steroids were then dissolved in $50 \mu \mathrm{L}$ of assay buffer. Plasma progesterone concentrations were measured by progesterone enzyme immunoassay. Tissue extract samples were diluted 10-fold in assay buffer to generate a standard curve, which ranged from 7.8 to 1000 $\mathrm{pg} / \mathrm{mL}$; the $\mathrm{ED}_{50}$ of the assay was $70 \mathrm{pg} / \mathrm{mL}$. Average intra- and inter-assay coefficients of variation were 13.9 and $9.6 \%$, respectively.

\section{Preparation of RNA and reverse transcriptase-polymerase chain reaction (RT-PCR) analysis of cFLIP mRNA}

Total RNA was extracted from CL tissues using an RNeasy mini kit (Qiagen, Chatsworth, CA, USA). Next, cDNA was synthesized from $1 \mu \mathrm{g}$ total RNA, using a commercial kit and oligo (dT) primers, according to the manufacturer protocol (Promega, Madison, WI, USA). Primers used for PCR on pooled cDNA samples were as follows: 5'-TCTGT GAACT TGGCT GAGCT GCTCT A-3' (cFLIP forward); 5'-TTTGC CCCAG ACTCA CCCTT-3' (cFLIP reverse); 5'-CCATC AGTGAAAAGTGCAGA AT-3' (cFLIP ${ }_{L}$ forward); and 5'-AGTGT GCTGC AGCCAGACGT A-3' ( $C F L I P_{L}$ reverse). Expression levels of glyceraldehyde-3-phosphate dehydrogenase (GAPDH) were determined in each sample for use as an internal control, using 5'-ATCCT GCCAA CATCA AGTGG-3' and 5'-GACAA TCTTG AGGGT GTTGT-3' forward and reverse primers, respectively. Product sizes expected from PCR amplification of $\mathrm{CFLIP}_{S}$, CFLIP $\mathrm{L}_{\mathrm{L}}$ and GAPDH were 472, 285, and 200 bp, respectively. 
Amplification by PCR was performed as follows: Platinum Taq DNA Polymerase (Invitrogen) was added to cDNA template with PCR mix that contained 1X PCR buffer, $0.1 \mathrm{mM}$ dNTP, $1.5 \mathrm{mM} \mathrm{MgCl}_{2}$, and $0.25 \mu \mathrm{M}$ of each primer. Using a PCR thermal cycler (GeneAmp PCR Systems 9700, PE Applied Biosystems) and a host-start PCR cycle for cFLIP ${ }_{S}$, CFLIP $_{L}$ and GAPDH, the following run conditions were used: 5 min denaturation at $94^{\circ} \mathrm{C} ; 30$ extension cycles of $30 \mathrm{~s}$ at $94^{\circ} \mathrm{C}, 30 \mathrm{~s}$ at $57^{\circ} \mathrm{C}$, and $30 \mathrm{~s}$ at $72^{\circ} \mathrm{C}$; and a $5 \mathrm{~min}$ final extension period at $72^{\circ} \mathrm{C}$.

All PCR products were electrophoresedon $1.5 \%$ agarose $(\mathrm{w} / \mathrm{v}) \mathrm{gel}$ (Cambrex Bio Science, Rockland, ME, USA) and stained with ethidium bromide (Wako, Osaka, Japan). Ready-load 100 bp DNA ladder (Invitrogen) was used as a molecular weight marker for electrophoresis, following which stained gels were recorded using a digital fluorescence-recorder (LAS-1000; Fuji Film, Tokyo, Japan). Expression levels of mRNA were estimated for each sample by the fluorescence intensity of PCR product bands, and quantified using Image-Gauge software (Fuji Film). The abundance of each specific mRNA was normalized to GAPDH mRNA levels in the same cDNA pool.

\section{Western blot analysis for cFLIP protein expression}

Corpus luteum samples were homogenizedon ice in UTD buffer (9 M urea and 1\% ( \pm )-dithiothreitol (DTT; w/v; both Wako), and 2\% Triton X-100 (v/v; Sigma Aldrich Chemicals, St Louis, MO, USA)), then stored at $-80^{\circ} \mathrm{C}$. Protein concentrations were quantified by the Bradford method using a Bio-Rad Protein Assay (Bio-Rad Laboratories, Hercules, CA, USA), then proteins solubilized in buffer solution (Wako) and heated at $95^{\circ} \mathrm{C}$ for $5 \mathrm{~min}$. For western blotting, aliquots of each solubilized protein fraction (30 $\mathrm{\mu g} / \mathrm{lane})$ were electrophoresed for $85 \mathrm{~min}$ at $200 \mathrm{~V}$ on a 10 to $20 \%$ gradient sodium dodecyl sulfate-polyacrylamide gel electrophoresis (SDS-PAGE, ATTO, Tokyo, Japan).Separated proteins were electrophoretically transblotted onto a polyvinylidine difluoride (PVDF) membrane (Millipore, Bedford, MA, USA) for $45 \mathrm{~min}$ at $25 \mathrm{~V}$. Membranes were stained with $0.2 \%$ Ponceau-S solution (w/v; Serva Electrophoresis, Heidelberg, Germany) and then immersed for $1 \mathrm{~h}$ at room temperature in blocking solution [10 mM Tris- $\mathrm{HCl}, \mathrm{pH} 8.0 ; 100$ $\mathrm{mM} \mathrm{NaCl} ; 0.1 \%$ Tween20 (v/v) and $2.5 \%$ bovine serum albumin (BSA; w/v; both Sigma Aldrich)]. After blocking, membranes were incubated at $4^{\circ} \mathrm{C}$ for $18 \mathrm{~h}$ with the following antibodies, diluted 1:100 in blocking buffer: for $\mathrm{CFLIP}_{\mathrm{L}}$, rabbit polyclonal anti-human $\mathrm{CFLIP}_{\mathrm{S} / \mathrm{L}}$ antibody (catalog no. sc-8347, Santa Cruz Biotechnology, Santa Cruz, CA, USA) was used; for cFLIP , anti-FLIP, NT rabbit polyclonal IgG antibody (human and mouse, catalog no. 06-697) was used. Membranes were then washed for $30 \mathrm{~min}$ in washing buffer $[10 \mathrm{mM}$ Tris- $\mathrm{HCl}, \mathrm{pH} 7.5 ; 100 \mathrm{mM} \mathrm{NaCl} ; 0.1 \%$ Tween $20(\mathrm{v} / \mathrm{v})$ ] then incubated for $1 \mathrm{~h}$ at room temperature with horseradish peroxidase (HRP)conjugated anti-rabbit IgG (Dako, Glostrup, Denmark) diluted 1:2000 in wash buffer. Expression levels of cFLIP-derived protein isoforms were visualized using an ECL western blotting detection reagents kit (RPN2209, GE Health care, UK). Chemiluminescence was recorded with a digital fluorescence recorder (LAS-1000, Fuji Film).

Using the same PVDF membrane, $\beta$-actin protein levels were examined for use as internal controls. Rabbit anti-human $\beta$-actin antibody (Abcam, Cambridge, UK), and HRP-conjugated antirabbit IgG (Dako), both diluted 1:2000 in blocking buffer, were used as primary and secondary antibodies, respectively. The chemiluminescent intensity of each protein band was quantified using Image-Gauge software (Fuji Film), and levels of cFLIP protein were normalized to those of $\beta$-actin in the same sample. 


\section{Tissue fixation and slide preparation}

Ovarian tissues were dehydrated in a graded series of ethanol solutions and embedded in paraffin wax. Embedded tissues were then serially sectioned into 4- $\mu$ m slices and mounted on glass slides pre-coated with 3-aminopropyltrimethoxysilane (Silane; Sigma Aldrich).

\section{Histology and immunohistochemistry}

Sections were stained with hematoxylin and eosin (H\&E) for examination of histology. For immunohistochemistry, sections were stained for cFLIP, proliferating cell nuclear antigen (PCNA) and terminal deoxynucleotidyl transferase-mediated biotinylated deoxyuridine triphosphate nick end-labeling (TUNEL), as outlined below.

\section{Immunohistochemistry for cFLIP}

Sections were dewaxed, rehydrated, washed in distilled water for 15 min,and then immersed in antigen retrieval buffer $\left(0.01 \mathrm{M}\right.$ citrate acid, $\mathrm{pH}$ 6) at $95^{\circ} \mathrm{C}$ for 10 min then at room temperature for $20 \mathrm{~min}$. In order to inhibit endogenous peroxidase, sections were treated with $0.3 \%$ hydrogen peroxide $\left(\mathrm{H}_{2} \mathrm{O}_{2} ; \mathrm{v} / \mathrm{v}\right)$ in methanol for $30 \mathrm{~min}$ then washed in PBS. Sections were incubated with normal goat serum diluted in PBS, in order to block non-specific protein binding, then incubated overnight at $4^{\circ} \mathrm{C}$ with rabbit anti-human $\mathrm{CFLIP}_{\mathrm{S} / \mathrm{L}}$ antibody (sc-8347, Santa Cruz Biotechnology) diluted 1:100 in PBS with 1\% BSA (w/v; Sigma Aldrich); negative control sections were incubated with PBS with 1\% BSA. Sections were then washed with PBS, and incubated for 30 min with biotinylated anti-rabbit IgG (Vector Laboratories, Burlingame, CA, USA) diluted 1:200 in PBS. Immunoreactivity was visualized using a VectaStain avidin-biotin-peroxidase kit (Vector Laboratories) for $60 \mathrm{~min}$ at room temperature, according to the manufacturer instructions. For color development, sections were washed thoroughly with PBS and then treated with Dako Envision Kit/HRP reagents (Dako). Finally, sections were washed with distilled water, counter-stained with methyl green, dehydrated, mounted with Entelan (Merck), and examined by light microscopy.

\section{Immunohistochemistry for PCNA}

Serial paraffin wax sections were dewaxed and then treated for 5 min with $3 \% \mathrm{H}_{2} \mathrm{O}_{2}(\mathrm{v} / \mathrm{v})$ in methanol, in order to inhibit endogenous peroxidase. Sections were washed with PBS and then incubated for $30 \mathrm{~min}$ at room temperature with horse serum diluted in PBS, in order to block nonspecific protein binding. Sections were incubated for $10 \mathrm{~min}$ at room temperature with mouse anti-rat PCNA monoclonal antibody (Dako), washed with PBS, and then incubated for $30 \mathrm{~min}$ at room temperature with biotinylated anti-mouse IgG (Vector Laboratories) diluted 1:200 in PBS. Immunoreactivity was visualized per the cFLIP protocol outlined above. Sections were treated for color development, counter-stained and mounted for examination by light microscopy, per the cFLIP protocol above. In each experimental run, adjacent sections were incubated without the addition of antibody, for use as negative controls.

\section{Detection of cellular apoptosis in histological sections}

Sections were stained for visualization of apoptotic cells by the TUNEL method, using 
an apoptosis in situ detection kit (ApopTag, Intergen, Manhattanville, NY, USA) according to the manufacturer protocol. In short, serial paraffin wax-embedded sections were dewaxed, washed in PBS for $10 \mathrm{~min}$, and then treated with Proteinase $\mathrm{K}$ solution for $20 \mathrm{~min}$ at room temperature. They were washed in distilled water and treated with $3 \% \mathrm{H}_{2} \mathrm{O}_{2}(\mathrm{v} / \mathrm{v})$ in methanol for $5 \mathrm{~min}$, in order to inhibit endogenous peroxidase. Sections were washed with PBS and then incubated in ApopTag equilibration buffer for 10 to $15 \mathrm{~min}$ at room temperature. They were then treated with terminal deoxynucleotidyl transferase (TdT enzyme) in a closed chamber for $60 \mathrm{~min}$ at $37^{\circ} \mathrm{C}$, immersed in stop wash buffer for $10 \mathrm{~min}$ at room temperature, washed in PBS, and then incubated with anti-digoxigenin conjugate for $30 \mathrm{~min}$. Sections were washed with $0.05 \mathrm{M}$ Tris- $\mathrm{HCl}$ buffer for $5 \mathrm{~min}$ and incubated with DAB solution for 10 to $30 \mathrm{~s}$, and then washed with distilled water. Finally, sections were counter-stained and prepared for examination by light microscopy as described for cFLIP above.

\section{Statistical analysis of data}

Homogeneity of variance across datasets was assessed using StatView-4.5 (Abacus Concepts, Berkeley, CA, USA). Using StatView-4.5, analysis of variance (ANOVA) with Fisher's least significant differences test was carried out for biochemical data, and Wilcoxon's signedrank tests for histological estimation. Differences at $\mathrm{P}<0.05\left(^{*}\right)$ or $\mathrm{P}<0.01\left({ }^{* *}\right)$ were considered statistically significant.

\section{RESULTS AND DISCUSSION}

\section{Hormone analysis}

Plasma progesterone concentrations were measured as described and are plotted as a time series (Figure 1). Progesterone concentrations increased significantly from day 0 to 3 , and remained high from day 3 to 17 of the estrous cycle. Concentrations decreased suddenly from day 17 onwards, during the regressed CL stage.

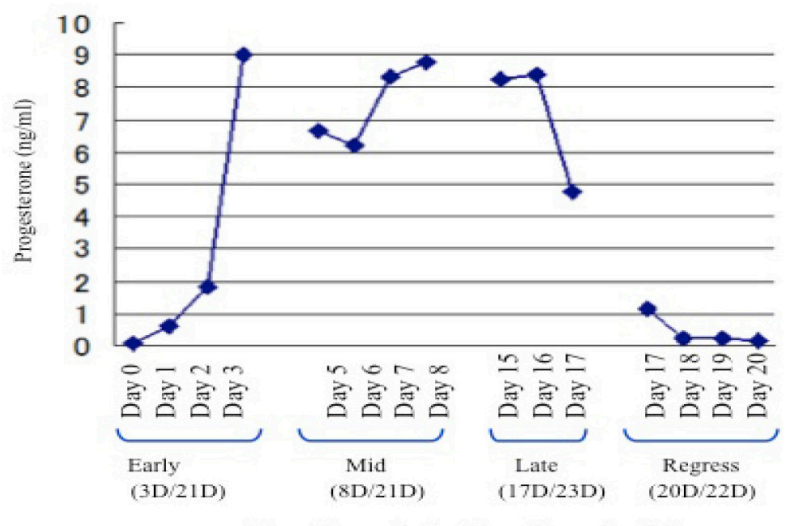

(Days after ovulation/day of sexual cycle)

Figure 1. Plasma progesterone concentrations throughout the estrous cycle of goats. Corpus lutea were assessed at early ( $E$, day 3 following ovulation); mid (M, day 8); late ( $L$, day 17$)$ and regressed ( $R$, day 20$)$ stages. The day of ovulation for each goat was designated day 0 ; this corresponded with days $21,21,23$, and 22 of the normal estrous cycle for each of the four goats. 


\section{cFLIP mRNA expression}

Both cFLIP ${ }_{S}$ and $c F L I P$ mRNA were expressed in the $C L$ of goats during the estrous cycle (Figure 2A). Normalized mRNA expression levels are shown in Figure 2B. Expression of $\mathrm{cFLIP}_{\mathrm{S}}$ mRNA was highest at the early CL stage, and decreased at the late and regressed stages $(P<$ 0.05). In contrast, $c F L I P_{L} m R N A$ levels were highest at the late $C L$ stage, and decreased at the regressed stage $(P<0.01)$.

\section{RT-PCR}

A

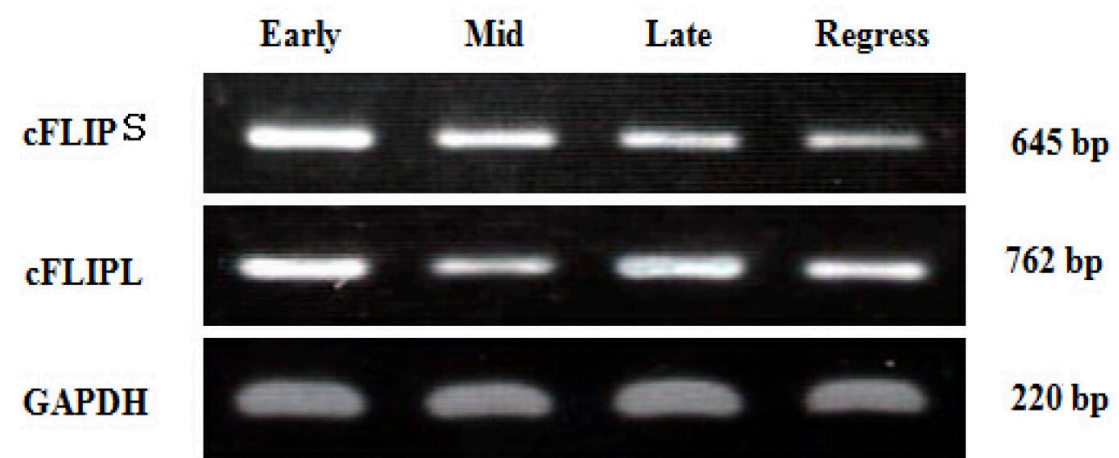

B
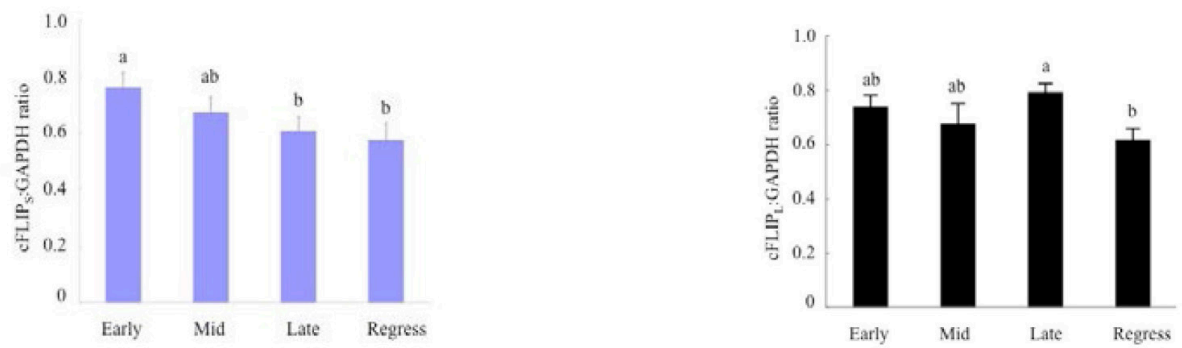

Figure 2. Expression of cFLIP mRNA throughout the estrous cycle of goats. Levels of $c F L I P P_{S}$ and $c F L I P, m R N A$ in early $(E)$, mid $(M)$, late $(L)$ and regressed $(R)$ corpus lutea were assessed by RT-PCR. Expression of GAPDH mRNA was measured in each sample as an intrinsic control. A representative image of electrophoresis is shown in (A). Expression of cFLIP was normalized to the GAPDH mRNA level (B). Data are shown as the mean \pm SEM. Small letters above data bars indicate significant differences $(P<0.05)$.

\section{cFLIP protein expression}

Western blot bands corresponding to $\mathrm{CFLIP}_{\mathrm{S}}$ and $\mathrm{CFLIP}_{\mathrm{L}}$ protein isoforms were observed at 28 and $55 \mathrm{kDa}$ (Figure 3A). Normalized expression levels are shown in Figure 3B. Expression of $\mathrm{CFLIP}_{\mathrm{S}}$ was consistently high at the early, mid and late $\mathrm{CL}$ stages, and decreased significantly at the regressed stage $(P<0.01)$. Expression of $C F L I P_{L}$ protein was highest at the early $C L$ stage, and decreased steadily during the mid, late and regressed stages $(P<0.01)$. 


\section{Western blot}

A
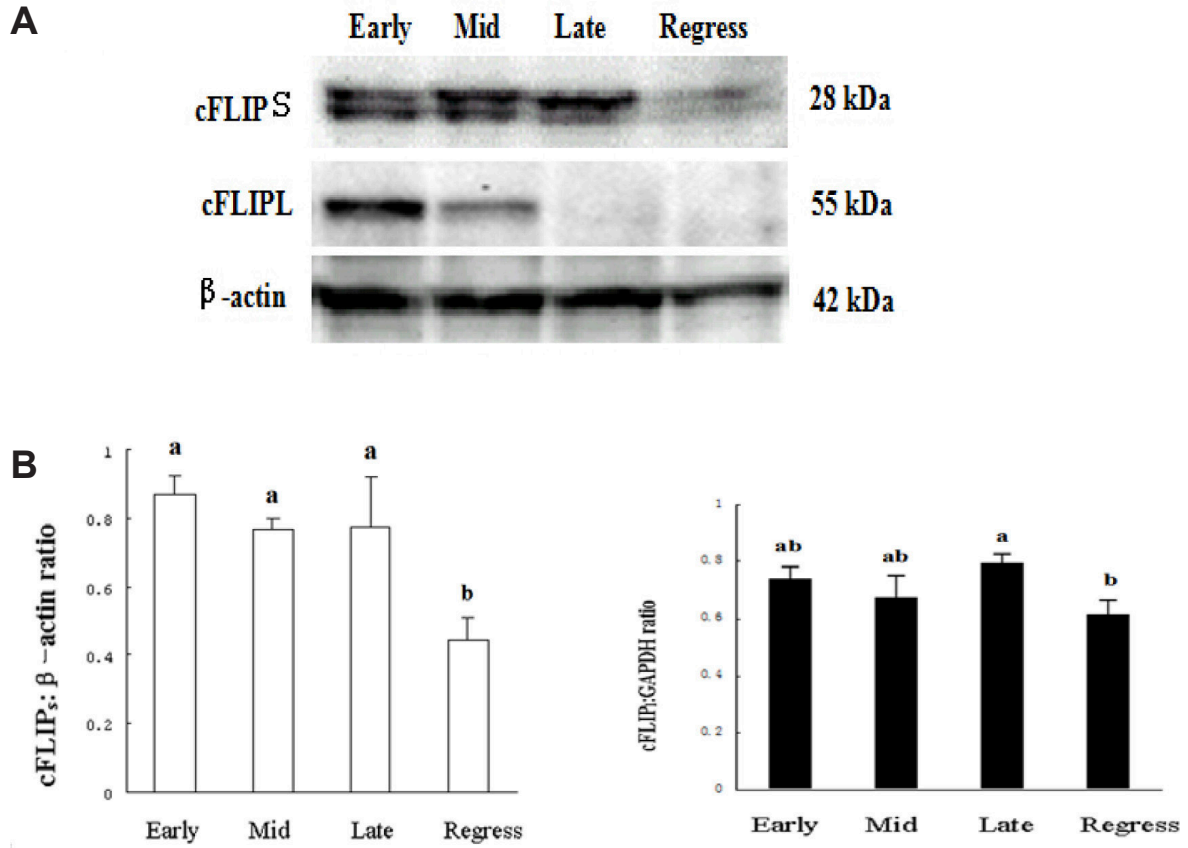

Figure 3. Expression of cFLIP protein throughout the estrous cycle of goats. Levels of $c F L I P_{S}$ and $c F L I P_{L}$ protein in early $(E)$, mid $(M)$, late $(L)$, and regressed $(R)$ corpus lutea were examined by Western blotting. A representative image is shown in (A); $\beta$-actin levels were measured in each sample as an internal control. Levels of $c F L I P_{S}$ and $c F L I P_{L}$ protein, normalized to $\beta$-actin levels, are summarized in (B). Data are shown as the mean \pm SEM. Small letters above data bars indicate significant differences $(P<0.01)$.

\section{Analysis of tissues by histology and immunohistochemistry}

Characteristics of luteal cells observed in H\&E stained tissue sections at the early, mid and late CL stages of the estrous cycle were within normal morphological limits (Figure 4A, E and I), while luteal cells at the regressed CL stage were atrophied (Figure 4M).

\section{Detection of cFLIP by immunohistochemistry}

Positive immunostaining for cFLIP was observed predominantly in the cytoplasm of luteal cells (Figure 4B-N). Immunostaining of luteal cells was strongest during the early, mid, and late $\mathrm{CL}$ stages (Figure 4B, F and J); only very pale staining was observed in the regressed stage (Figure 4N).

\section{Detection of PCNA by immunohistochemistry}

Immunostaining for PCNA was strongly positive in the early CL stage (Figure 4C); we akin the mid and late stages (Figure 4G and K); and absentin the regressed stage (Figure 4O). 


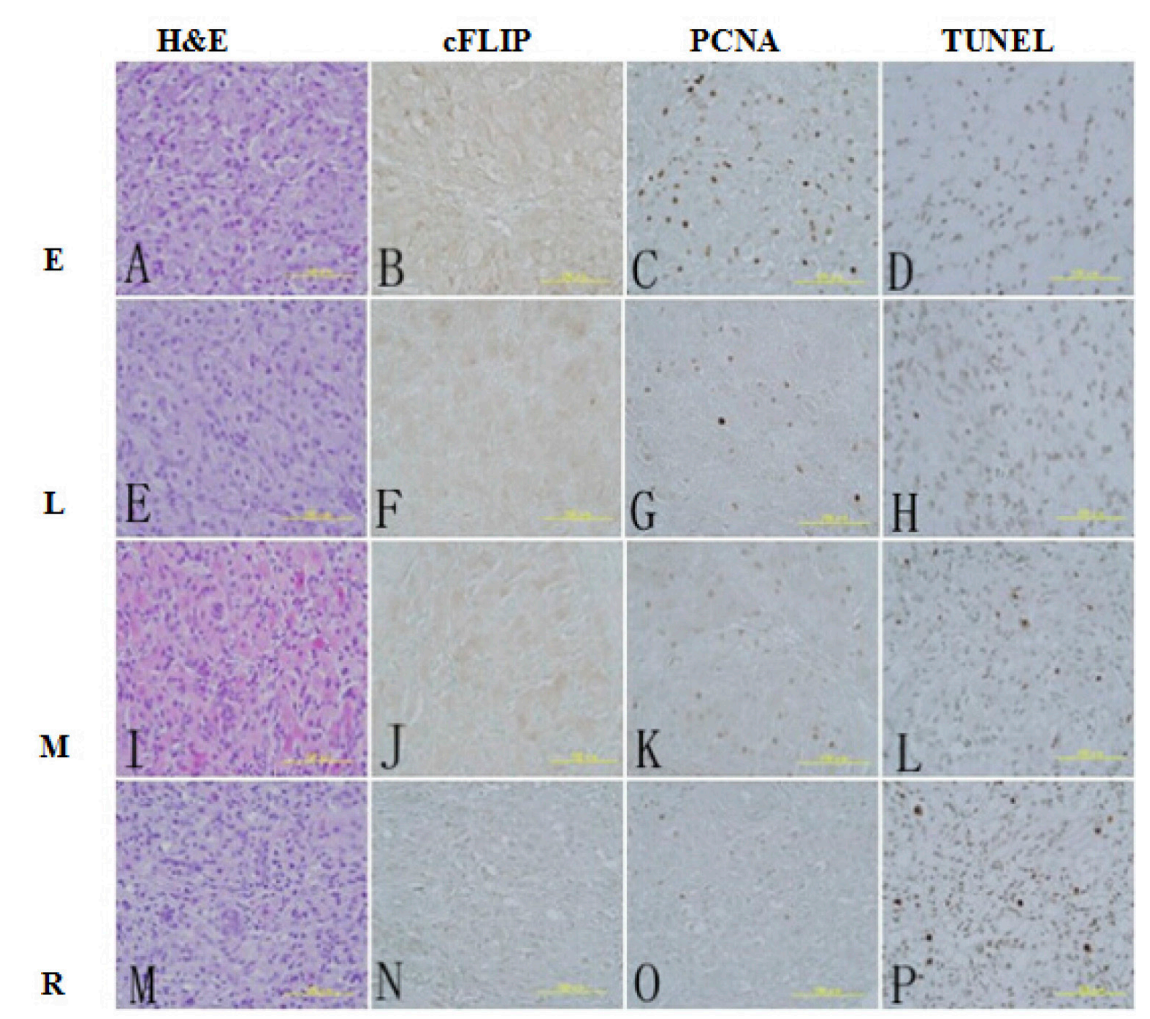

Figure 4. Immunohistochemical methods were detected by H\&E (A, E, I, M), cFLIP (B, F, J, N), PCNA (C, G, K, O) and TUNEL (D, H, L, P). The sections were from early (A-D), mid (E-H), late (I-L) and regression (M-P) corpus luteum stage during estrous cycle in goats. The morphology of luteal cells was shown normal at the early $(A)$, mid $(E)$ and late (I) CL stages by H\&E stain. The cFLIP positive was seen in the early $(B)$, mid $(F)$ and late $(J) C L$ stages. The PCNA-positive was seen in the early $(C)$, mid $(D)$ and late $(K)$ CL stages.In regressed $C L$ stage, the morphology of luteal cells was atrophic $(M)$; no staining of CFLIP $(N)$ and PCNA $(O)$, TUNEL-positive $(P)$ was detected. Sections were counterstained with methyl green. An arrow indicates a positive. A, B, C and D; E, F, G and H; and I, J, K and L, respectively, were serial sections. Scale bar $=100 \mu \mathrm{m} 400 \mathrm{X}$.

\section{Detection of apoptotic cells}

Numerous TUNEL-positive cells were observed in tissue sections from the regressed $\mathrm{CL}$ stage (Figure 4P), and a few cells in the late stage (Figure 4L). Cells in the early and mid CL stages of the estrous cycle were all negative for TUNEL staining (Figure 4D and $\mathrm{H}$ ).

\section{DISCUSSION}

During reproductive life, apoptosis plays an important role in the demise of the majority of mammalian gonadal cells (follicular granulose and luteal cells in ovaries, and germ cells in testes) (Manabe et al., 2004). The luteolytic process is normally subdivided: a decline in progesterone (as presented in Figure 1) is described as functional luteolysis, while structural/cellular involution is described as structural luteolysis (Sugino and Okuda, 2007). In the present study, we used 
RT-PCR and Western blotting to examine the expression of cFLIP in the ovarian CLof Shiba goat throughout the estrous cycle, in order to determine the role of cFLIP in ovarian luteal tissue. Expression of cFLIP mRNA and protein (Figures 2 and 3) generally showed their highest levels during the early and mid CL stages of the estrous cycle. Much lower expression was observed in regressed CL. Plasma progesterone concentrations increased significantly from day 0 to 3 , was high from day 3 to day 17 , and declined suddenly from day 17 (the regressed CL stage) of the estrous cycle. These results indicate that cFLIP expression may be related to progesteronesignaled stages of CL development, and is perhaps directly involved in CL function. At the early, mid and late CL stages of the estrous cycle, luteal cells appeared normal by histopathological examination, but were atrophied during regression from days 17 to 20 . Upon assessment of tissues by immunohistochemistry, cellular expression of cFLIP was localized in the luteal cells, and PCNApositive reactions were observed in many luteal cells in the early $\mathrm{CL}$ stage, but in few luteal cells in mid and late stages. In direct contrast, apoptotic cells were not present during the early and mid CL stages; small numbers were observed in the late CL stage, and many in the regressed CL stage (the point at which H\&E staining showed that the luteal cells were atrophied).

Based on the relationship between luteal cell morphology and immunohistochemical characteristics, it appears that cFLIP proteins may be involved in determining the histological morphology of CL of mammalian ovaries, by maintaining functionality in luteal cells. During luteolysis, the different cell components of the CL begin to undergo apoptosis. This process has been described for humans, cows, pigs, mice, and golden hamsters (Jo et al., 1995; Bacci et al., 1996; McCormack, 1998; Davis and Rueda, 2002; Kliem et al., 2009). Previous results suggest that luteolysis involves loss of function and subsequent involution of the luteal structure.

Our new data are in agreement with a previous report in which both short and long isoforms of cFLIP were shown to prevent apoptosis (Irmler et al., 1997). However, our data do not correspond with those of another study, which demonstrated that $C F L I P_{L}$ is the most abundant isoform expressed in the porcine granulosa cells (Matsuda-Minehata et al., 2005). It has been previously demonstrated that over-expression of $\mathrm{CFLIP}_{S}$, but not $C F L I P_{L}$, prevented apoptosis of granulosa cells in rats (Xiao et al., 2001). These observed inconsistencies may high light interspecies or inter-cell differences in cFLIP isoform expression.

The results presented here are in accord with previous observations that both short and long cFLIP isoforms can prevent apoptosis in the porcine CL. However, our findings indicate that high expression of $C F L I P_{L}$ protein at the early $C L$ stage may be a species-level phenomenon.

We therefore conclude that cFLIP acts as an anti-apoptotic factor and inhibits intracellular apoptotic signaling by competing with its homologue, procaspase-8, an upstream inducer of apoptosis activated by TNF family-death ligands (including TNF- $\alpha$, FasL and TRAIL) (Krueger et al., 2001). We further hypothesize that in goats, cFLIP inhibits procaspase-8 recruitment to FADD, thereby blocking death receptor-mediated apoptosis. It has been previously established that cFLIP is more efficient than any other anti-apoptotic gene (such as TRAF1, TRAF-2, cIAP-1, and clAP-2) in preventing death receptor-mediated cell death (Wang et al., 1998). In the present study, we have demonstrated that expression of cFLIP in the caprine CL is high in healthy CL, and decreased at the regressed $C L$ stage. This is in accordance with the temporal requirements of an anti-apoptotic role of cFLIP in CL development and maintenance throughout the estrous cycle of Shiba goats.

\section{Conflicts of interest}

The authors declare no conflict of interest. 


\section{ACKNOWLEDGMENTS}

Research supported by the National Natural Science Foundation of China (grant \#31260529) and the Natural Science Foundation of Jilin Province (grant \#20150204079NY).

\section{REFERENCES}

Bacci ML, Barazzoni AM, Forni M and Costerbosa GL (1996). In situ detection of apoptosis in regressing corpus luteum of pregnant sow: evidence of an early presence of DNA fragmentation. Domest. Anim. Endocrinol. 13: 361-372.

Bowen JM, Towns R, Warren JS and Landis Keyes P (1999). Luteal regression in the normally cycling rat: apoptosis, monocyte chemoattractant protein-1, and inflammatory cell involvement. Biol. Reprod. 60: 740-746.

Davis JS and Rueda BR (2002). The corpus luteum: an ovarian structure with maternal instincts and suicidal tendencies. Front. Biosci. 7: d1949-d1978.

Hughes FM Jr and Gorospe WC (1991). Biochemical identification of apoptosis (programmed cell death) in granulosacells: evidence for a potential mechanism underlying follicular atresia. Endocrinology 129: 2415-2422.

Irmler M, Thome M, Hahne M, Schneider P, et al. (1997). Inhibition of death receptor signals by cellular FLIP. Nature 388: 190-195.

Juengel JL, Garverick HA, Johnson AL, Youngquist RS, et al. (1993). Apoptosis during luteal regression in cattle. Endocrinology 132: $249-254$.

Jo T, Tomiyama T, Ohashi K, Saji F, et al. (1995). Apoptosis of cultured mouse luteal cells induced by tumor necrosis factoralpha and interferon-gamma. Anat. Rec. 241: 70-76.

Johnson AL and Bridgham JT (2002). Caspase-mediated apoptosis in the vertebrate ovary. Reprod. 124:19-27.

Kano Y, Sawasaki T and Oyama T (1977). Biological characteristics of miniature "Shiba" goats. Exp. Anim. 26: 239-246.

Krueger A, Baumann S, Krammer PH and Kirchhoff S (2001). FLICE-inhibitory proteins: regulators of death receptor-mediated apoptosis. Mol. Cell Biol. 21: 8247-8254.

Krueger A, Schmitz I, Baumann S, Krammer PH, et al. (2001). Cellular FLICE-inhibitory protein splice variants inhibit different steps of caspase-8 activation at the CD95 death-inducing signaling complex. J. Biol. Chem. 276: 20633-20640.

Komatsu K, Manabe N, Kiso M, Shimabe M, et al. (2003). Soluble Fas (FasB) regulates luteal cell apoptosis during luteolysis in murine ovaries. Mol. Reprod. Dev. 65: 345-352.

Kliem H, Berisha B, Meyer HH and Schams D (2009). Regulatory changes of apoptotic factors in the bovine corpus luteum after induced luteolysis. Mol. Reprod. Dev. 76: 220-230.

Mori Y and Kano Y (1984). Changes in plasma concentrations of LH, progesterone and oestradiol in relation to the occurrence of luteolysis, oestrus and time of ovulation in the Shiba goat (Capra hircus). J. Reprod. Fertil. 72: 223-230.

McCormack JT, Friederichs MG, Limback SD and Greenwald GS (1998). Apoptosis during spontaneous luteolysis in the cyclic golden hamster: biochemical and morphological evidence. Biol. Reprod. 58: 255-260.

Mogi K, Li JY, Suzuki M, Sawasaki T, et al. (2002). Characterization of GH pulsatility in male Shiba goats: effects of postpubertal castration and KP102. Endocr. J. 49: 145-151.

Manabe N, Goto Y, Matsuda-Minehata F, Inoue N, et al. (2004). Regulation mechanism of selective atresia in porcine follicles: regulation of granulosa cell apoptosis during atresia. J. Reprod. Dev. 50: 493-514.

Matsuda-Minehata F, Goto Y, Inoue N and Manabe N (2005). Changes in expression of anti-apoptotic protein, cFLIP, in granulosa cells during follicular atresia in porcine ovaries. Mol. Reprod. Dev. 72: 145-151.

Nagata S (1997). Apoptosis by death factor. Cell 88: 355-365.

Rueda BR, Wegner JA, Marion SL, Wahlen DD, et al. (1995). Internucleosomal DNA fragmentation in ovine luteal tissue associated with luteolysis: in vivo and in vitro analyses. Biol. Reprod. 52: 305-312.

Roughton SA, Lareu RR, Bittles AH and Dharmarajan AM (1999). Fas and Fas ligand messenger ribonucleic acid and protein expression in the rat corpus luteum during apoptosis-mediated luteolysis. Biol. Reprod. 60: 797-804.

Shikone T, Yamoto M, Kokawa K, Yamashita K, et al. (1996). Apoptosis of human corpora lutea during cyclicluteal regression and early pregnancy. J. Clin. Endocrinol. Metab. 81: 2376-2390.

Sakamaki K, Yoshida H, Nishimura Y, Nishikawa S, et al. (1997). Involvement of Fas antigen in ovarian follicular atresia and luteolysis. Mol. Reprod. Dev. 47: 11-18.

Sakurai K, Ohkura S, Matsuyama S, Katoh K, et al. (2004). Body growth and plasma concentrations of metabolites and metabolic hormones during the pubertal period in female Shiba goats. J. Reprod. Dev. 50: 197-205.

Sugino $\mathrm{N}$ and Okuda K (2007). Species-related differences in the mechanism of apoptosis during structural luteolysis. $J$. Reprod. Dev. 53: 977-986. 
Tilly JL, Kowalski KI, Johnson AL and Hsueh AJ (1991). Involvement of apoptosis in ovarian follicular atresia and postovulatory regression. Endocrinology 129: 2799-2801.

Thome M and Tschopp J (2001). Regulation of lymphocyte proliferation and death by FLIP. Nat. Rev. Immunol. 1:50-58.

Wang CY, Mayo MW, Korneluk RG, Goeddel DV, et al. (1998). NF-kappaB antiapoptosis: induction of TRAF1 andTRAF2 and C-IAP1 and C-IAP2 to suppress caspase-8 activation. Science 281: 1680-1683.

Xiao CW, Asselin E and Tsang BK (2001). Nuclear factor kappaB-mediated induction of Flice-like inhibitory protein prevents tumor necrosis factor alpha-induced apoptosis in rat granulosa cells. Biol. Reprod. 67: 436-441. 